\title{
Mechanical Performance Analysis on Bamboo Fiber Reinforced Polyester Composite
}

\author{
R. SundaraKannan, V. Arumugaprabu, V. Manikandan
}

\begin{abstract}
The present study narrates about the performance of bamboo fiber against polymer matrix. Among different natural fibers bamboo proved to be a potential ones for effective composite production. Based on this aspect this research carried out by using bamboo fiber of length $5 \mathrm{~mm}$ in chopped form as reinforcement unsaturated polyester used as matrix. The studies were done by varying the bamboo fiber weight percentage as 20,30 and $40 \%$ weight respectively. The prepared specimens are subjected to tensile strength, flexural strength and Impact strength studies. Based on the results obtained this composite suggested for suitable application.
\end{abstract}

Keywords : Bamboo fiber, polyester composites, Tensile strength, Flexural strength, Impact strength and Hardness.

\section{INTRODUCTION}

$\mathrm{T}$ here are various kinds of natural fibers such as banana(1), bamboo, wheat(2) and coconut(3). Fibers are used as reinforcing material. These natural fibers contains high specific gravity and not cause any hazards. Bamboo fiber is one of the most commonly used natural fiber. $45 \%$ of bamboo forest is located in India (4). Bamboo is fastest growing tree compared to other natural fibers. Due to arrangement of cellulose in length wise the bamboo fiber has high tensile strength. These bamboo commonly found on the tropical countries. It can be used as cheapest alternate for wood. The bamboo fiber has good moisture absorption. The bamboo needs 8 month to obtain a full growth. The distribution of density in bamboo fiber varies plant to plant. The mechanical properties might change when the moisture content is the natural fiber is $20-25 \%$. Hence these natural fibers has many advantage one among them is they are recyclability. The polyester resin used here is from polymer family. These polymer are classified into two types namely saturated and un - saturated. This polymer has resistance to water and also to other chemicals. Compared to other resigns it has very low shrinkage of $4-8 \%$ at the time of curing. Sanjay K et al stated that short bamboo fiber reinforced polypropylene composite by means of increasing the volume of fiber from $30-50 \%$ the tensile strength has increased(4).

Revised Manuscript Received on December 5, 2019

R. SundaraKannan, Research Scholar in the Department of Mechanical Engineering, School of Automotive and Mechanical Engineering, Kalasalingam Academy of Research Education, Krishnank oil, Tamilnadu, India.

V. Arumugaprabu, Associate Professor Department of Mechanical Engineering, School of Automotive and Mechanical Engineering, Kalasalingam Academy of Research and Education, Krishnankoil, Tamilnadu, India.

V. Manikandan, Professor in Kalasalingam Academy of Research and Education
Anu gupta et al discovered that bamboo fiber reinforced epoxy composite has increased flexural strength by adding $20 \%$ of fiber (5).Tingju $\mathrm{Lu}$, et al investigated that bamboo fiber is been treated with $\mathrm{NaOH}$ before they were applied into epoxy composites shows an improvement in tensile strength [6]. Sameer Awad et al inferred that adding of flour to that polyethylene increases the flexural strength by $0.5 \%$ (7).

\section{MATERIALS AND METHODS}

Polyester resin used as a matrix purchased from vasivabala resin. PVT limited Chennai, India. Bamboo fiber is purchased from Jeeva fiber, Chennai. Iron mould is coated with wax and the bamboo fiber is separated, filled inside the iron mould. The inner diameter of iron mould is $3 \mathrm{~mm}$ filled with fiber after that resin is taken and methyleethyle ketone peroxide of $4 \mathrm{ml}$ taken and stirred for $10 \mathrm{mins}$. Now the mixture is poured in the mould and kept the compression moulding machine at pressure 120 bar for 4 hours as shown in figure1. After 4 hours the composite is separated from the mould. The obtained composite undergone the Impact test, flexural test, hardness test and tensile test. The fabricated bamboo filled polyester composite plate is shown fig 2 .

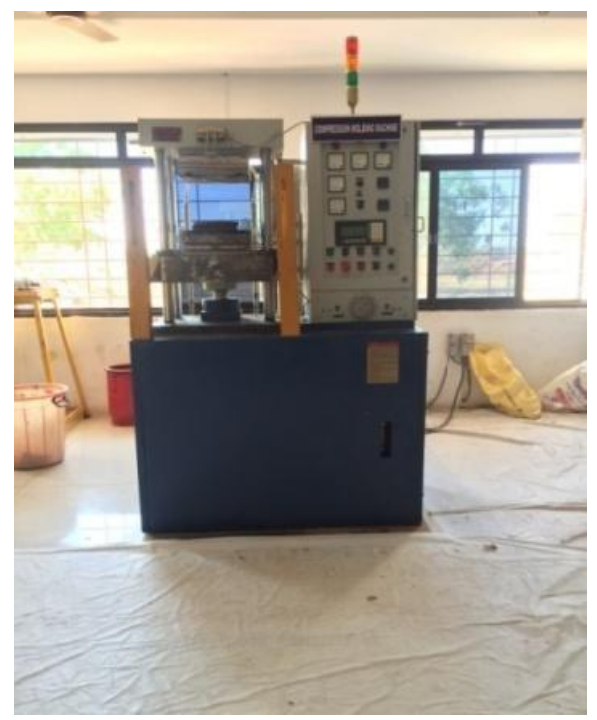

Fig. 1. Compression Moulding Machine 


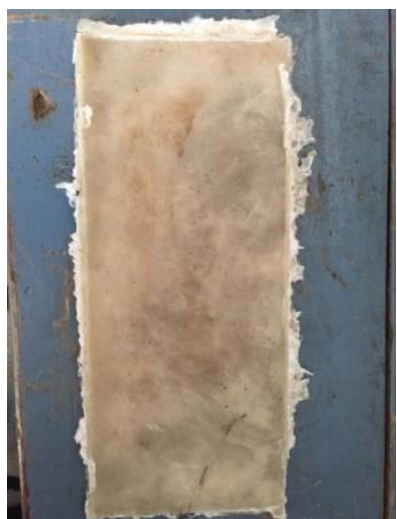

Fig. 2. Bamboo fiber reinforced composite

\section{RESULTS AND DISCUSSION}

\section{A. Tensile strength}

Tensile behavior of bamboo fiber reinforced polyester composites is shown in figure. Different loadings on bamboo fiber and their tensile strength performance was compared with pure polyester. Generally polyester was a brittle material and natural fiber incorporated into the strength. Among the different fiber loading $40 \mathrm{wt} \%$ shows an enhanced strength of $30 \mathrm{Mpa}$. When compared to pure polyester. In the case of $20 \%$ wt addition also a slight increase in strength noted. Both cases good adhesion between fiber and matrix happens. On the other hand whereas the $20 \%$ wt fiber loading shows a sudden decrease in strength. This is due to the fiber arrangement which is randomly oriented yields scattering of fiber due to the compression force. This results in poor strength the tensile strength increases by $11 \%$ with the addition of bamboo fiber as reinforcement.

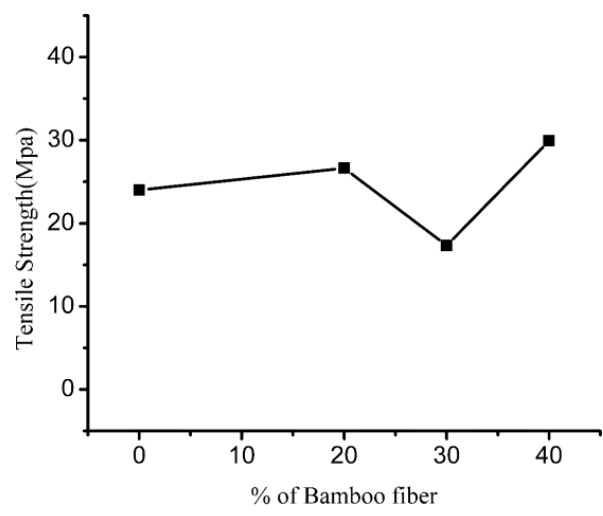

\section{Fig. 3. Tensile strength of bamboo fiber reinforced polyester composites}

\section{B. Flexural strength}

The flexural strength results were plotted as in figure 4 . The trend is same like the tensile strength where addition of $20 \%$ and $40 \%$ wt fiber increases the flexural strength but $30 \% \mathrm{wt}$ addition decreases the strength. The ability to withstand bending force varies drastically with respect to fiber orientation and fiber percentage is strongly evident through previous research. Here the randomly oriented bamboo fiber not able to withstand bending force in the case $30 \% \mathrm{wt}$ addition where the fibers not hold strongly by the matrix gives poor strength. On the other hand the remaining $40 \% \mathrm{wt}$ addition shows an improvement in strength due to the better bonding between fiber and matrix. The flexural strength increases by $22 \%$ with the addition of bamboo fiber as reinforcement.

Fig. 4. Flexural strength of bamboo fiber

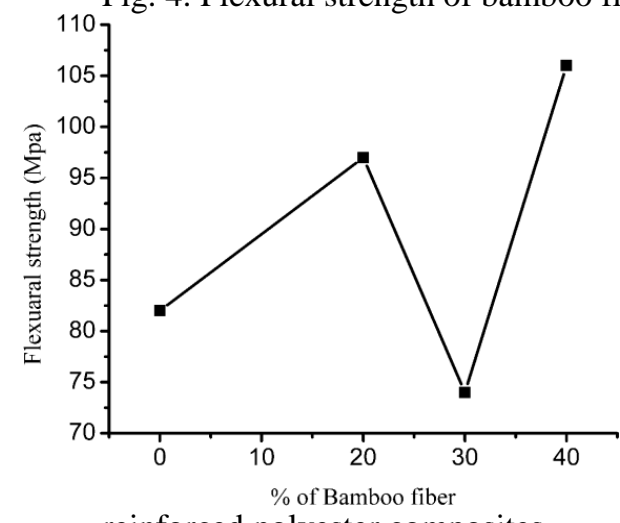

reinforced polyester composites

\section{Impact strength}

The impact energy absorbed by the addition of bamboo fiber as reinforcement is shown in fig 5 . The trend is same as that of tensile and flexural results. More amount of energy absorbed by the addition of $20 \%$ and $40 \%$ wt bamboo fiber reinforcement in which a strong bonding occurs between the matrix and reinforcement which yields good energy absorbing capacity. In the case of $30 \%$ wt bamboo fiber the poor dispersion results in low energy absorb which in term gives poor strength. The impact strength increases by $11 \%$ with the addition of bamboo fiber as reinforcement.

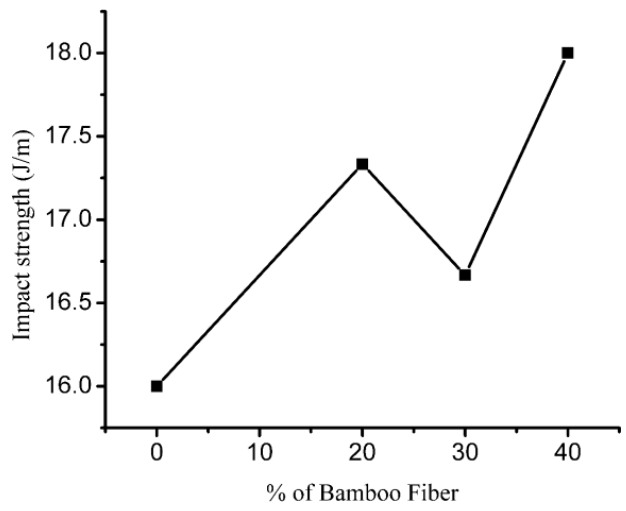

Fig. 5. Impact strength of bamboo fiber reinforced polyester composites

\section{Hardness}

The hardness values of prepared bamboo fiber polyester composites are shown in figure. The polyester matrix was normally a semi crystalline matrix. So, it was revealed that, hardness values 61 . The addition of $20 \%$ and $40 \%$ reinforcement increases the hardness values of the composite. The hardness value increased by $11 \%$ with addition of bamboo fiber reinforcement.

Published By: 834 Blue Eyes Intelligence Engineering 


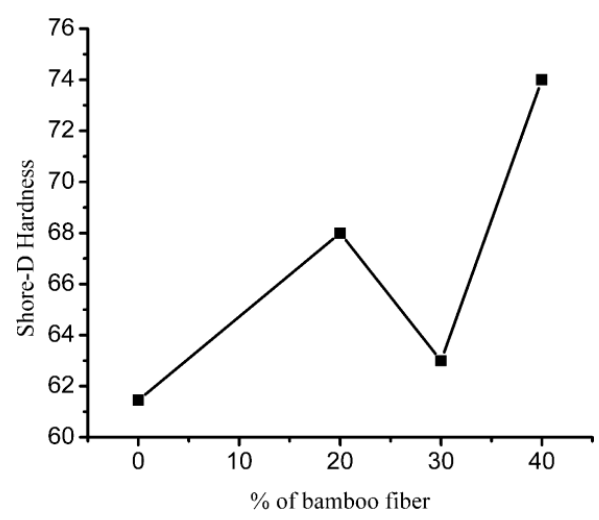

Fig. 6. Hardness strength of bamboo fiber reinforced polyester composites

\section{CONCLUSION}

- Different percentage bamboo reinforced polyester matrix were successfully produced by compression moulding technique.

- Adding bamboo can increase the hardness properties of composite and maximum hardness attained at $40 \%$ wt reinforcement.

- In the case of $30 \%$ wt bamboo fiber the poor dispersion results in low energy absorb which in term gives poor strength. The impact strength increases by $11 \%$ with the addition of bamboo fiber as reinforcement.

- The tensile strength increases by $11 \%$ with the addition of bamboo fiber as reinforcement.

- The flexural strength increases by $22 \%$ with the addition of bamboo fiber as reinforcement.

- This type of composite may be suitable for light weight application.

\section{REFERENCES}

1. L. A. Pothan, S. Thomas and N. R. Neelakantan, "Short banana fiber reinforced polyester composites: mechanical, failure and aging characteristics," Journal of Reinforced Plastics and Composites, 16(8), 1997, 744-765.

2. T. Kunanopparat, P. Menut, M. H. Morel and Guilbert, S Reinforcement of plasticized wheat gluten with natural fibers: from mechanical improvement to deplasticizing effect. Composites part A: Applied science and manufacturing, 39(5), 2008, 777-785.

3. C. Y. Lai, S. M. Sapuan, M. Ahmad, N. Yahya and K. Z. H. M. Dahlan, "Mechanical and electrical properties of coconut coir fiber-reinforced polypropylene composites," Polymer-Plastic Technology and Engineering, 44(4), 2005, 619-632.

4. S. K. Chattopadhyay, R. K. Khandal, R. Uppaluri and A. K. Ghoshal, "Bamboo fiber reinforced polypropylene composites and their mechanical, thermal, and morphological properties," Journal of Applied Polymer Science, 119(3), 2011, 1619-1626.

5. A. Gupta, A. Kumar, A. Patnaik and S. Biswas, "Effect of different parameters on mechanical and erosion wear behavior of bamboo fiber reinforced epoxy composites," International Journal of Polymer Science, 2011

6. T. Lu, M. Jiang, Z. Jiang, D. Hui, Z. Wang and Z. Zhou, "Effect of surface modification of bamboo cellulose fibers on mechanical properties of cellulose/epoxy composites," Composites Part B: Engineering, 51, 2013, 28-34.

7. S. Awad and E. Khalaf, "Modified performance of mechanical, thermal, and physical properties of high-density polyethylene-corn flour composites," Usak University Journal of Engineering Sciences, 1(1), 2018, 38-46.

\section{AUTHORS PROFILE}

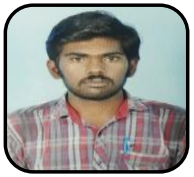

First Author R. Sundarakannan is a Research Scholar in the Department of Mechanical Engineering, School of Automotive and Mechanical Engineering,Kalasalingam Academy of Research Education, Krishnankoil, Tamilnadu, India. He graduated B. Tech in Mechanica Engineering in the year 2015, Graduated M.Tech in Engineering Design in the year 2017 both at Kalasalingam University, India. His area of research is polymer-based composites.

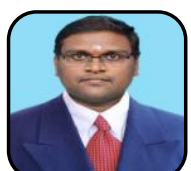

Second Author V. Arumugaprabu working as Associate Professor in the Department of Mechanical Engineering, School of Automotive and Mechanical Engineering, Kalasalingam Academy of Research and Education, Krishnankoil, Tamilnadu, India. He graduated B.E in Mechanical Engineering at AKCE in the year 2005, Graduated M.E in CAD/CAM at MepcoSchlenk Engg., college ,Graduated Ph.D in Composite Materials in the year 2014 at Kalasalingam, krishnanakoil. He has very vast research experience in the field of composite materials with nearly 35 publications in various reputed SCI Journals.

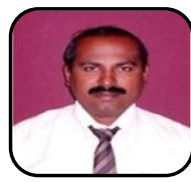

Third Author Dr. V. Manikandan working as a Professor in Kalasalingam Academy of Research and Education. He has 28 years' experience in teaching and research.He had published 51 journal paper and 20 conference paper in the field of composite materials. 